\title{
Improving the environmental culture of employees at the enterprise, based on the environmental management system and sustainable development principles
}

\author{
Maria Ostapenko ${ }^{1, *}$ and Umida Kholboeva ${ }^{1}$ \\ ${ }^{1}$ Industrial University of Tyumen, Tyumen, Russia.
}

\begin{abstract}
Culture is an integral part of human formation, and environmental culture determines a person's willingness to make environmentally friendly decisions in all areas of activity. It is the level of ecological culture that determines the practical readiness to responsibly treat the environment of both employees and managers. To this end, this article explores the problem of an insufficient level of ecological culture development of employees and managers of enterprises that entail a deterioration in the environment quality. When studying this topic, special attention has been paid to the implementation of an environmental management system based on the sustainable development principles. The methods to increase the interest of managers in the introduction and implementation of the environmental management system, based on the European Union experience, and ways to improve the environmental culture of employees in the enterprise are analyzed. The result of the study is practical and theoretical methods for improving environmental culture, based on early scientific research in this area and personal opinions of the authors.
\end{abstract}

\section{Introduction}

There are a lot of studies related to environmental problems due to human activity and its impact on the environment, but it is worth noting the insufficient number of studies on human culture, namely the development of ecological culture, which is a formative factor in preserving the environment and reducing the negative impact of a person on it. Due to the increase in industrial organizations, and with this increase in the negative impact of man on the environment, it becomes relevant to use green production methods and reduce resource consumption, but these factors are not enough to green the industry and reduce the negative impact of men on nature. To reduce the negative consequences, enterprises are introducing an environmental management system (hereinafter referred to as EMS), built on the principles of sustainable development and allowing to maximally ecologize the existing processes at the enterprise and reduce the negative impact of humans on the environment. In turn, sustainable development is defined as 'development that meets the needs of the present

\footnotetext{
* Corresponding author: ms ostapenko@mail.ru
} 
generation without compromising the ability of future generations to satisfy their own needs' [3]. Thus, implementation of EMS is an integral part of the greening of processes at the enterprise.

When implementing the system, the state of such a factor as the environmental culture of employees and management is often not considered, nevertheless, this factor is the main factor in the further work of the system. In turn, it is culture that is a factor in the formation of a person and his actions based on internal beliefs and attitudes. In the book Human Behavior and Ecology, culture is defined as a combination of three positions that complement each other and express the concept of 'culture'. The first defines culture as the lifestyle of a certain group of people, the second as a system of symbols and cognitive patterns transmitted through symbolic codes, the third as a set of adaptive survival strategies related to ecology and resource consumption [1], Markaryan gives another definition of culture as reflecting social life of people from the point of view of an inherent or specific mode of activity, embracing that particular system of means and mechanisms due to which human individuals in the process of cooperated existence solve various problems that confront them [9]. Consequently, culture can be considered as one of the main factors determining human activity, and in this article, we will consider the culture that forms careful attitude to nature and its resources, called environmental culture. Shishkina in her study defines ecological culture as a process of a person's awareness of his natural and the same time social life, believing that it is formed throughout life and is part of education. [6]

Ecological culture should develop in a person gradually, without abrupt transitions, since it is difficult for a person to rebuild his or her life positions based on anthropocentrism, in this study we studied the methods of phased education of ecological culture and methods of motivating managers to implement these processes. Thus, the above methods can be applied by managers in the implementation of EMS and can also be supplemented and improved during testing.

\section{Implementation of EMS at the enterprise}

The human environmental culture has always been an important problem for mankind, however, some consider it a waste of time, others - an inefficient use of resources. Somehow, environmental culture remained overlooked. Unexplored properly, this problem entailed a few others. The state of ecological culture especially manifests itself in production, when an employee negatively affects the environment, without realizing his responsibility. Thus, he does not only pollute the environment, but also harms the image of the company where he works. As a result, improving environmental culture is becoming an urgent task that needs to be developed in all areas of activity.

Research by scientists has found that environmental disasters caused by insufficient environmental knowledge kill more people than any other natural disasters. Thus, the number of premature deaths caused by environmental pollution, according to 2017, reached 9 million people. Harmful emissions into the air lead to cardiovascular diseases, stroke, lung cancer. Contamination of water sources causes gastrointestinal diseases and parasitic diseases. An important source of problems is harmful working conditions, for example, the need to work with carcinogens [4,2]. Therefore, it is very important to reduce the negative impact of both a person on the environment and the impact of environmental problems on his body.

Such problems do not go unnoticed, many world organizations pay attention to the greening of life and all processes taking place in it. For example, in 1992, within the framework of the Global Ecological Forum, the sustainable development principles were formulated, which subsequently gave a huge impetus to the development of environmental culture. 
Based on the principles of sustainable development, one of the most important series of international standards has been built, which ensures the implementation of a system that allows greening processes in the enterprise. The international standards of ISO 14000 series, designed to regulate the environmental processes occurring in the enterprise, are the most effective methods of greening processes. Introducing the international standard ISO 14001:2015 (the official translated version - MS GOST R ISO 14001-2016), the enterprise implements a whole system according to which all processes on it will work according to PDCA principle and apply a systematic approach. The process of continuous improvement allows the company to plan, maintain, evaluate, and constantly improve the environmental management processes at the enterprise. Such a structure should contribute to the long-term success of the organization and the achievement of the common goal of sustainable development. A systematic approach to environmental management can provide quantitative and qualitative data to senior management, which makes it possible to make informed business decisions, build long-term success and create opportunities for sustainable development. The success of the environmental management system depends on the commitment of all levels and units of the organization, managed by senior management [10].

Russia does not stand aside and is actively developing environmental policy by introducing new international standards and improving legislation in the field of greening, but do these actions give their result? Every year, Yale University conducts large-scale studies in the field of environmental efficiency, which measures the achievements of countries in terms of the state of ecology and natural resource management on the basis of 22 indicators in 10 categories that reflect various aspects of the state of the environment and the viability of its ecological systems, conservation of biological diversity, combating climate change, the state of public health, the practice of economic activity and the degree of its load on the environment, as well as the effectiveness of state policy in the field of ecology. Russia in this ranking as of 2016 occupied 32nd place, but already in 2018 it fell to 52nd place, this implies that the ecological condition of Russia is deteriorating every year [5.8]. Consequently, we should increase the interest of industrial enterprises in the environmental management system implementation and realize the goals of sustainable development.

GOST R ISO 14001-2016 standard is an adapted analogue of the international standard ISO14001:2015, which is implemented by Russian enterprises as an environmental management system. However, obtaining a certificate of compliance does not always ensure the implementation and further work of a complex environmental management process. Since this certificate is a prerequisite for entering the world market, many enterprises receive a certificate of compliance, without further work of the process. Most often, managers do not see a benefit in implementing an environmental management system, considering the process ineffective. However, the effective work of the process depends not only on the work of the ecologist at the enterprise, this complex process involves development of the employees' environmental culture and leadership of managers in this matter. In accordance with Section 4 of EMS, the leadership of the management is an integral part of the implementation of EMS in the enterprise, and the manager must be interested and committed to the implemented system. Most of the work depends on the leader's leadership and his interest in introducing the environmental management process, since it is the manager who sets the pace in the greening of processes at the enterprise. В свою очередь, заинтересованность руководителя и персонала зависят от степени экологической культуры человека. In turn, the interest of the manager and staff depends on the degree of environmental culture of a person. Thus, the main and important factor in the ecologization of life and processes at the enterprise is ecological culture, which in many cases is not developed at all, and the lack of a clear structure for improving the ecological culture at the enterprise aggravates the deplorable situation in the world. 


\section{Practical and theoretical methods for the development of environmental culture}

To build a clear and efficient environmental management system, of which the human environmental culture is part, it is worth starting with the interest of the manager in this matter. As previously mentioned, most often enterprise managers implement an environmental management system for the sake of profit, but even this factor can be used to green the processes in the enterprise. Based on an analysis of the methods used by European countries to improve environmental friendliness of processes in the enterprise, as well as to increase commitment of the manager, several activities that can be useful both in our country and at our enterprises are presented below.

First, it is necessary to build a legislative structure that supports the work of 'green companies' using alternative methods of generating energy. Namely, the use of the types of energy that have the least impact on the environment. These methods include the use of solar panels and windmills. As a result, receiving energy in an alternative way, companies receive benefits from the state in the form of reduced taxes, provision of state subsidies and other methods of maintaining 'green companies'.

You can also introduce tax differentiation methods. It consists in adapting taxes based on the environmental friendliness of goods: they increase for 'environmentally dirty' and decrease for 'environmentally friendly' goods. An example is fuel taxes, based on its polluting characteristics.

The system of environmental quotas, trade in pollution rights. Limitations can be quantified as the maximum level of pollution, the rights to which can be sold ('cap and trade') or as the minimum indicator of efficiency for obtaining quotas ('baseline and credit'). Quotation is considered as a market-based instrument, requiring a detailed environmental and economic assessment of the objects and subjects of this process, allowing enterprises to receive income from the sale of unrealized pollution rights.

Soft loans. Several foreign banks, non-profit financial organizations and state funds provide preferential financing for enterprises introducing resource-saving technologies, carrying out developments in the field of energy conservation, optimizing their activities in accordance with the principles of sustainable development [7].

The above methods of motivating enterprises, or rather managers in organizing a management system, will contribute to the further development of greening processes and life in the enterprise. The manager, who is interested in greening the processes, in turn, will contribute to the implementation and continuous improvement of the environmental management system and the concept of sustainable development.

An important role in improving the environmental culture of enterprises is to instill it in all employees. The following methods are examples by which you can improve the environmental culture of employees in the enterprise.

The initial stage in the upbringing of ecological culture, of course, is the family, because in the family a person receives the earliest knowledge about the world around him, on this basis it is worth promoting an environmentally friendly lifestyle in families, a conscious rejection of non-environmentally friendly products, replacing vehicles with a more environmentally friendly method of transportation, conducting excursions and nature trips, where children and parents will more deeply understand their impact on the environment, parents, learning with their children, will use the experience gained at work. In this part, preschool and additional education can be useful, through organization of various groups, etc.

The company may apply elements of gamification. Game forms of learning contribute to learning in a relaxed atmosphere, which contributes to a freer acceptance of new information. This method involves training employees by analyzing the current situation at the enterprise and proposing their own methods for solving problems. Participants will be given 
assignments (cases) and with the help of 'brainstorming' they will be offered to find a solution to the existing problem.

Besides, the company should organize 'green corners' where employees can take care of plants and enjoy fresh air during breaks from work. The 'greening' of the enterprise buildings has a positive effect on the general condition of employees and on the perception of partners and customers at the enterprise level, thereby increasing its image.

Placing infographics in crowded places promotes cultivation of an ecological culture in a person, by placing posters about human impact on the environment and ways to reduce harm, the employee is provided with general information that he can use at work in the future. Conscious consumption and understanding of the impact on the ecological state of the employee will give an impetus to the development of environmental culture.

The possibility of creating atriums in large enterprises for employees will have a beneficial effect on them, thus a love of nature arises and a person begins to perceive it not as something for granted, but as a product of many years of work. The involvement of employees in landscaping atriums can contribute to a better understanding of the processes occurring in nature, as well as understanding of their impact on it.

The system of fines and bonuses at the enterprise may have the last and fastest effect, of course, this method is not the most effective, since it does not imply conscious work of a person on his ecological culture, but will give an impetus to the development of these skills for gaining benefits.

The proposed methods can be supplemented by 'green days' at the enterprise, lectures and error correction, but it is worth considering the fact that the upbringing of ecological culture mainly depends on the person himself, and also it should be laid back, because often people themselves do not understand this mechanisms of work, not being aware of what they are doing.

\section{Conclusion}

Ecological culture is not just a set of human competencies, not a way of working; ecological culture is a complex of knowledge, experience, mainly a person's awareness of his or her environmental impact. Ecological culture should be taught and introduced at every enterprise, and the state should support projects aimed at its development. The above methods of improving environmental culture should be implemented in accordance with the principles of sustainable development, as well as the environmental management system. Thus, this contributes to the correct perception of new information and a more correct implementation of the system, which in the future will allow to green all processes in the enterprise. Subsequently, the greening of the processes will not only improve the environment of the region, but also increase the economic efficiency of the enterprise, and mainly reduce environmental problems, leading to increased mortality. The recommendations for further research may be the introduction of the proposed methods, as well as their consideration from a practical point of view, this approach will enable you to get the results of effectiveness of the methods used.

\section{References}

1. Irvin A., Rapoport A., Wohlwill J. F., Human Behavior and Environment ADVANCES IN THEORY AND RESEARCH, New York : PlenumPress, (1980)

2. Naked Science, https://naked-science.ru/article/sci/zagryaznenie-okruzhayushcheysredy, (20 October 2017 г.)

3. Oxford, Oxford University Press, (1987) 
4. The Lancet Commission on pollution and health, https://www.thelancet.com/commissions/pollution-and-health, (19 October 2017 г.)

5. University, Yale, Environmental Performance Index, https://epi.envirocenter.yale.edu/epi-country-report/RUS, (2018)

6. Shishkina E.A., Sociocultural practices as a factor in the formation of environmental culture. Sociologicheskie issledovanija [Sociological studies], No. 9, pp. 79-84, (September 2008)

7. Toxina E.V., Stimulation of greening the economic activities of enterprises: concept, tools, models. Rostov-on-Don: Southern Federal University, (2019)

8. Ecological rating of countries, https://nonews.co/directory/lists/countries/ecology, (2018)

9. Markaryan E.S., Systematic study of human activity, Voprosy filosofii [Philosophy Issues], pp. 106-120, (1972)

10. GOST R ISO 14004-2017 Environmental Management Systems. General Implementation Guidelines - Introduction. 2018-05-01, Moscow: Gosstandart Rossii Publ., (2018) 